\title{
SOME FACTORS IN THE DEVELOPMENT OF THE AMPHIBIAN EAR VESICLE AND FURTHER EXPERI- MENTS ON EQUILIBRATION
}

\author{
$\mathrm{B} \mathbf{Y}$ \\ GEORGE L. STREETER, M.D. \\ Associate Professor of Neurology at the Wistar Institute \\ With Six Figures
}

In a previous paper concerning experiments on the developing ear vesicle ${ }^{1}$ it was shown that the group of cells forming the primitive epithelial ear cup or ear vesicle of the tadpole is specialized to that degree that although removed to an abnormal environment the cells still continue to differentiate themselves into a structure possessing many of the features of a normal labyrinth. Recently it has been shown by Lewis ${ }^{2}$ that even earlier, while still an uninvaginated plate, the ear anlage is already capable of a certain degree of independent differentiation. In the following paper additional evidence will be given of the high degree of developmental independence possessed by the early labyrinth cells. It will be pointed out that individual parts of the vesicle may develop independently of the rest of the vesicle. It will also be shown that the process of differentiation extends to the difference existing between a right and left-sided organ. A left ear vesicle transplanted into the empty pocket left by the removal of the right ear vesicle develops into a labyrinth that is perfect in general form and in its relations to the brain, with the exception that it maintains its left-sided character; the anterior semicircular canal is found on the caudal side toward the vagus group, while the posterior canal lies toward the eye, and likewise the lagena which

\footnotetext{
${ }^{1}$ Streeter, G. L., 'o6: Some experiments on the developing ear vesicle of the tadpole with relation to equilibration. Jour. of Experimental Zoöl, vol. iii.

${ }^{2}$ Lewis, W. H., 'o7: On the origin and differentiation of the otic vesicle in amphibian embryos. Anatomical Record, No. 6, Amer. Jour. of Anat., vol. vii.

The Journal of Experimental Zoölogy, vol. iv, no. 3 .
} 
normally buds out from the caudal border of the saccule in these cases is found extending forward toward the proötic ganglion.

The ear vesicle, however, is not in all respects independent of the surrounding structures. Some experiments which are reported below, indicate that its position in reference to the brain, ganglion masses and the surface of the body is determined by the environment itself; it may be rotated in any direction, and nevertheless it eventually develops in the normal attitude, with the saccule toward the ventral surface, the semicircular canals toward the dorsal surface, the lateral semicircular canal being toward the lateral surface, and the endolymphatic appendage toward the brain.

The experiments were carried out on larve of Rana sylvatica and Rana pipiens, and the operating stage was the same that was used in previous experiments. ${ }^{3}$ The time is just at the close of the non-motile stage, and the epithelial ear consists of an invaginated cup-shaped mass of cells just in the process of being pinched off from the deeper layer of the skin, with the edges turning in to form a closed vesicle. For simplicity the term "ear vesicle" will be used even though the closure is not yet complete; the attempt to distinguish between auditory cup and auditory vesicle does not seem to be justified for the present purposes. The technique of the operations was also the same as that described in the previous paper. Notes were made on the behavior of the animals, and at the end of from four to six weeks the specimens were preserved in a chrome-acetic mixture, cut in serial sections, and staned with hrmatoxylin and congo red. With certain specimens the ear vesicle, adjacent ganglia, and a portion of the central nervous system were reconstructed after the Born wax plate method. Eleven such models were made, and photographs of some of them are reproduced in Figs. 2, 3 and 6. With the aid of these models it was possible to identify relations and detailed features of the labyrinths that otherwise could not have been recognized.

The morphological features of the experiments will be first considered, and the behavior of the animals and its relation to equilibrium will be treated separately in the latter part of the paper.

${ }^{3}$ Streeter 'o6: I. c., Fig. 3, p. 547. 
DETERMINATION OF POSITION OF THE EAR VESICLE

The conclusion that the attitude of the developed labyrinth, the position of its canals and various chambers, is determined by its environment is based on seventeen experiments in which the ear vesicle was loosened from its normal situation and placed in an abnormal attitude, and the specimen then allowed to continue in its development. At the end of a month examination showed that the labyrinth had become differentiated with varying degrees of completeness, and in each instance had developed in normal relation to the surrounding structures.

Rotation in Two Directions. In eight of these experiments the ear vesicle was rotated $180^{\circ}$ around both its vertical and transverse axes, so that it was turned face inward and upside down; or, in other words, its lateral or invaginated surface was toward the brain and its ventral border was where the dorsal border should be, the maximum displacement. After this procedure the wounds healed within a few hours, and the larvæ were reared up to the fourth or fifth week, when they were killed and cut in serial sections. The labyrinths of five specimens were reconstructed. Before describing them reference should be made to the normal condition of the labyrinth at this age. A reconstruction of a normal one with its adjacent structures is shown in Fig. I.

From the reconstruction of a normal specimen it can be seen that the three semicircular canals have individual characteristics by which they can be separately identified; such as the Y-shaped union of the anterior and lateral canals, and the overlapping of the caudal end of the lateral canal by the posterior canal, and the junction of the posterior and anterior canals to form the crus commune. The differentiation between utricle and saccule is not yet complete, but the part that is to become saccule is so labeled. From the caudal border of the saccule can be seen a small pocket budding out which constitutes the lagena or primitive cochlea. Directly median to the crus commune is the endolymphatic appendage, consisting of a small duct leading from the main labyrinth chamber up between the labyrinth and brain to a rounded pouch, the saccus endolymphaticus. In their histology, as well as in 
their general form, the various parts of the labyrinth exhibit at this time individuality. (See Fig. 4.) The ventro-median portion of the vestibular sac and the ampullar ends of the semicircular canals possess high columnar cells forming the neuro-epithelial maculæ which are supplied with fibers from the acoustic ganglion, lying against the medial wall of the labyrinth. The endolymphatic sac has cuboidal cells, and the lagena has intensely staining columnar cells like those seen in the macular regions. The lagena is further characterized by its sharply rounded outline, and by the fact of its being compactly surrounded by ganglion cells and fibers, and cartilage forming cells. These features are so definite that

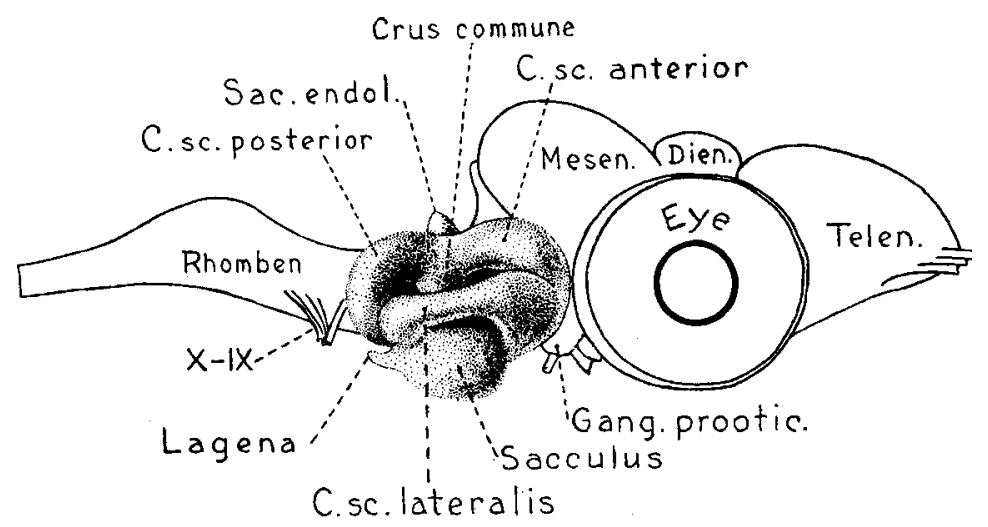

Fig. I Reconstruction showing the form and relations of the membranous labyrinth of a normal tadpole (Rana pipiens) one month old. The labyrinth, adjacent ganglia and part of the brain were reconstructed after the Born method, and the remainder of the figure was drawn from a dissection of a tadpole of the same age. Enlarged 35 diameters.

the various parts of the labyrinth can be recognized without diffculty, even though they happen to be incomplete, or out of their normal relations.

Now if one examines the models of the operated specimens, photographs of three of which are reproduced in Fig. 2, it is seen that the individuality of the semicircular canals can at once be identified. In model $a$, the canals are practically normal; in model $b$, the anterior canal is small, and the lateral canal consists only of a pouch which has not been pinched off from the main cavity; in model $c$, the posterior canal remains a simple pouch, while the 
anterior and lateral canals are normal. In considering the posture of the canals it is to be noted that the surrounding structures have been left out in Fig. 2, to avoid unnecessary duplication; the three models are all represented in the same relative position as that of the labyrinth in Fig. I, i.e., the cephalic end is on the right, the caudal end is on the left, the ventral surface is below, and the dorsal surface is above. Thus it will be seen that the lateral canals in all three models are in the same plane; likewise the posterior canals all form the dorso-caudal border of the labyrinth, and the anterior canals form the dorso-cephalic border. The fact that the anterior canal is small in model $b,{ }^{4}$ and the posterior canal is small in model $c$, gives rise to a false impression of a backward sac. endolymph.

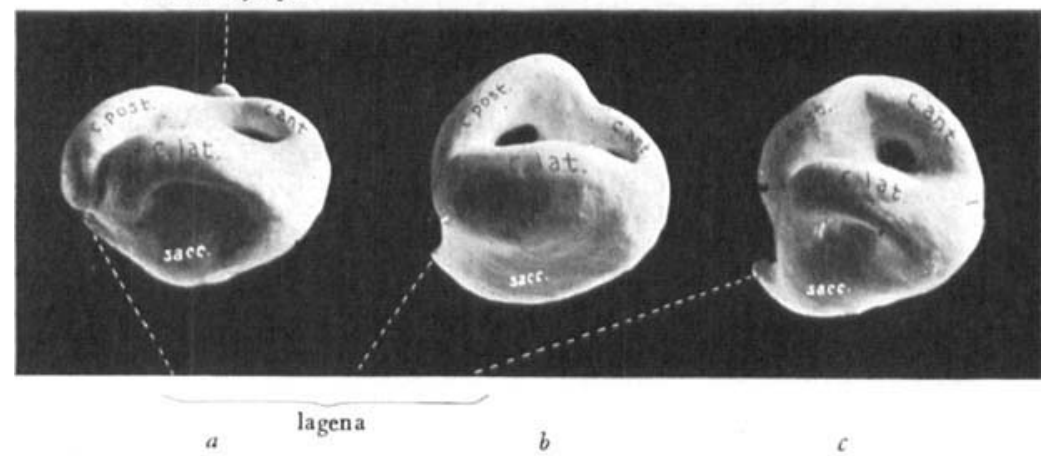

Fig. 2 Reconstructions showing the form and posture developed by three labyrinths one month old, which while primitive ear vesicles were rotated from their normal position so as to lie face inward and upside down. The models are placed so that their planes are parallel with those in Fig. $\mathbf{x}$. Thus they present a lateral view with the cephalic end toward the right, caudal end toward the left, dorsal surface above, and ventral surface below. Enlarged $5^{\circ}$ diameters.

and forward tilting of the vesicle. The saccule and lagena have the same position as in Fig. I, and the lagena points caudally as it should do. The endolymphatic appendage lies on the median side of the crus commune; in models $b$ and $c$ it is small, but the tip

\footnotetext{
${ }_{4}^{4}$ This may be due to injury received at the time of operation. Such localized defects are frequently seen. They may involve any part of the labyrinth, and they vary greatly in the extent of the labyrinth wall affected. In one case the entire labyrinth was defective, with the exception of the endolymphatic appendage, which was normal in structure and position, and presented a curious appearance, being

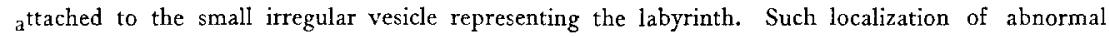
fevelopment is evidence of the high degree of specialization of the cells forming the primitive ear vesicle.
} 
of it can be seen in model $a$. The acoustic nerve and ganglion are attached to the median and ventral surfaces of the labyrinth, and the nerve connection with the brain appears to be normal.

The conditions found in the three specimens pictured in Fig. 2 are typical of what is found in the other five specimens examined. They vary in the completeness of their differentiation, some of them consisting of only a vesicle with perhaps a single canal pouch, but in all cases the acoustic ganglion is present on the ventro medial surface, and the macular areas can be recognized. The lagena is present in seven out of eight cases. The endolymphatic appendage developed in six out of eight cases. As regards posture, the rule is that the more perfectly the labyrinth is developed the more accurately its posture corresponds to the normal relations. But even in the most imperfect specimens when the endolymphatic appendage appears it is on the medial surface, and the tendency to canal formation is always on the dorso-lateral surface, and the saccule and lagena appear on the ventral surface. This condition of course applies only to vesicles that have been implanted in the acoustic region as was done in all the above cases.

Rotation in One Direction. In four experiments the ear vesicle was rotated $\mathrm{I} 80^{\circ}$ around its vertical axis, i.e, turned face inward. These specimens were then reared as in the preceding instance, and eventually cut in serial sections. A reconstruction model of one of them is reproduced in Fig. 3, and if it is compared with Fig. $I$ it will be seen that although the vesicle was started in its development with invaginated side toward the brain yet the completed labyrinth has the normal posture. A section of the same specimen is reproduced in Fig. 4, showing the labyrinth surrounded by developing cartilage. The acoustic ganglion is connected in normal manner with the brain and sends peripheral fibers to the thickened floor of the saccule. The endolymphatic sac is in its normal position, and the narrow duct can be seen connecting it with the main chamber of the labyrinth directly median to the crus commune. The series through this specimen show that histologically it is practically perfect. Of the other three specimens one was almost equally perfect, another showed some abnormalities in the formation of the canals and the lagena, and the 
fourth was quite imperfect, consisting of only a large vesicle with a thickened epithelial floor connected by a few nerve cells and fibers with the brain.

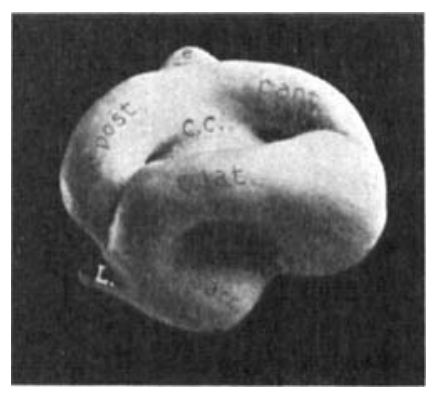

Fig. 3 Reconstruction of a tadpole labyrinth one month old, which when a primitive ear vesicle was rotated from the normal position $180^{\circ}$ in one direction, so as to lie with invaginated side toward the brain. A section through the same labyrinth is shown in Fig. 4. Enlarged 55 diameters.

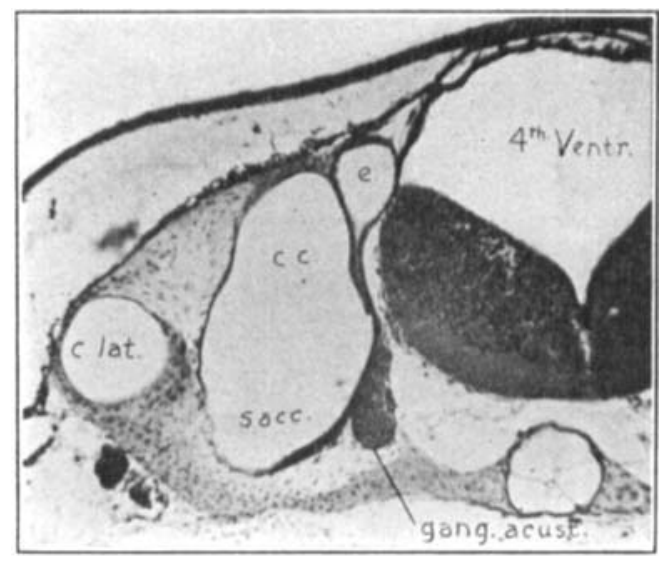

Fig. 4 Section through the membranous labyrinth shown in Fig. 3. It shows that though originally turned face inward it has developed in the normal attitude. $e$, endolymphatic appendage; c.c., crus commune; sacc., saccule; c. lat., lateral semicircular canal; gang. acust., acoustic ganglion. Enlarged 55 diameters.

Transplanted Specimens. The irregularity of form of the six specimens transplanted to the region between the eye and nostril, previously reported, ${ }^{3}$ is so great that they give no assistance in solv-

Streeter 'o6, i. c., p. 557 . 
ing the question of posture. However, in five cases, which will be presently described, where the ear vesicle was transplanted from the left side to the right side into the place made vacant by the removal of the right ear vesicle, in spite of the fact that these ear vesicles were implanted with haphazard attitude toward the adjacent structures, they nevertheless in each instance developed right-side up, and with the median surface toward the brain, as can be seen in Figs. 5 and 6.

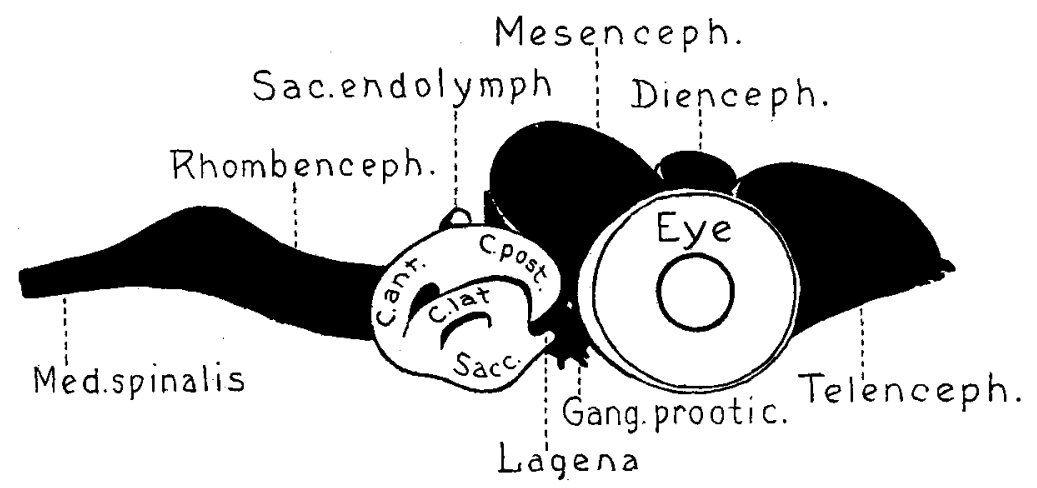

Fig. 5 Reconstruction showing the form and relations developed by a left ear vesicle when transplanted to the right side; it shows that under such circumstances the ear vesicle retains its left-sided characteristics, though it otherwise normally adapts itself to its new situation. A photograph of the same specimen is shown in Fig. 6, c.

\section{DETERMINATION OF THE DEXTRAL AND SINISTRAL CHARACTER OF THE EAR VESICLE}

The question as to whether the right or left-sidedness of the ear labyrinth is controlled by the environment, or is determined by some intrinsic character of its own constituent cells, is answered in favor of the latter by the fact that if the left primitive ear vesicle, before the time of its complete closure, is transplanted to the opposite side of the embryo it retains its original left-sidedness. In five specimens, at the usual operating stage, the right ear vesicle was removed, and at the same time the left ear vesicle was uncovered and lifted from its natural bed and then placed into the pocket 


\section{Development of Amphibian Ear Vesicle}

from which the right vesicle had been taken and allowed to heal. In making the transplantation no effort was made to place the ear vesicles in any particular posture. After keeping the specimens alive for one month they were sectioned and from three of them reconstructions were made of the transplanted ear vesicle together with the adjacent structures. The three labyrinths are shown in Fig. 6, and model $c$ is again shown in Fig. 5, with the brain included. It will be seen that in developing they have assumed the normal attitude toward the brain. The endolym-

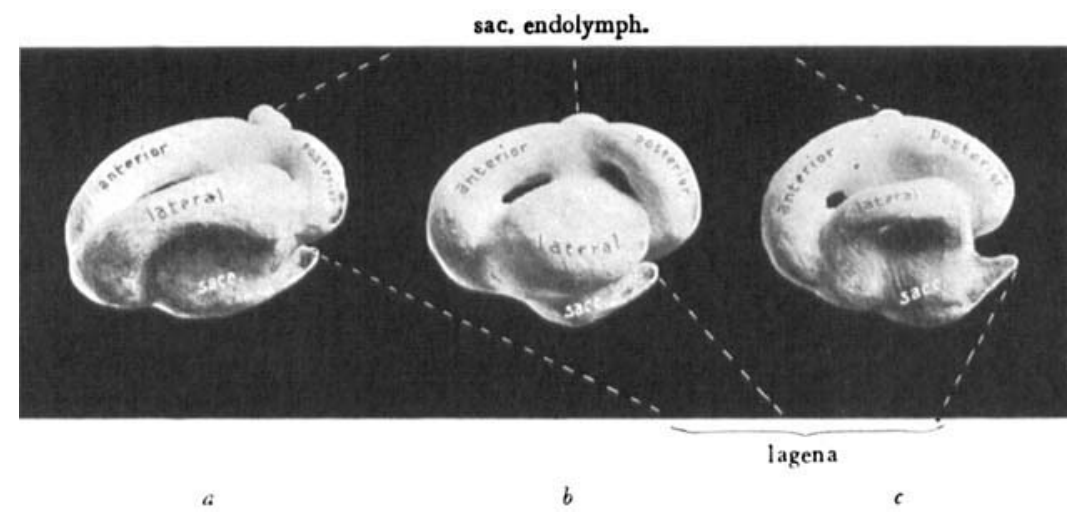

Fig. 6 Reconstructions of three labyrinths which while primitive ear vesicles were transplanted from the left to the right side. They are all represented in the same position as the models in Fig. 2. The model $c$ is the same that is shown in Fig. 5. Enlarged 50 diameters.

phatic appendage and the median side of the labyrinth is toward the brain, the semicircular canals are toward the dorso-lateral surface, and the saccule and lagena are toward the ventral surface. But it can at once be recognized that the saccule and lagena point forward toward the eye, and that the anterior and posterior canals are in reversed positions. We thus have a complete mirror image of the right labyrinth, i. e., a left labyrinth. Model $a$ possesses three semicircular canals and is almost a normally formed left labyrinth. In model $b$ the lateral canal consists of a pouch whose walls did not undergo the customary approximation and central absorption. In model $c$ the posterior canal is not pinched off. In each of the models the lagena, saccule, and endolymphatic 
appendage are typical, and there is establishment of normal appearing nerve and ganglion connections.

\section{EQUILIBRATION}

It was found in the experiments performed a year ago that removal of one or both ear vesicles, just after they are pinched off from the skin, produces in the tadpoles definite disturbances in the development of their power of equilibration. It was found that when a tadpole is deprived of but one ear vesicle he is by virtue of the remaining one able to develop practically normal swimming abilities; but when both ear vesicles are removed the results are more serious, and in that case the tadpole never develops any sense of equilibrium and is never able to swim. The loss is not compensated for by any other organ and the animal lies helpless on the bottom of the dish. With one ear vesicle the tadpole swims practically in normal fashion, and with no ear vesicle he cannot swim at all.

The fact that one ear vesicle is sufficient for the maintenance of equilibrium greatly simplifies the study of this mechanism; it means that one side can be immediately eliminated, and the problem is reduced from a bilateral one to a unilateral one. A series of experiments at once suggested themselves, in which the ear vesicle of one side was to be removed, and then various operative procedures undertaken upon the ear vesicle of the opposite side, and the test of its consequent functional ability was to be the very decisive one of whether the animal could swim properly, or whether it could not swim at all.

In the paper referred to there is described the experiment of transplanting the ear vesicle into a subdermal pocket in front of the eye. When this was done the transplanted ear vesicle continued in its development, and in some instances established a nerve-ganglion connection with the forebrain; but such specimens never gave evidence of functional activity. The failure to functionate was not unexpected, inasmuch as the connections established were at an abnormal situation, and furthermore the vesicles though having developed many essential features of the normal labyrinth 


\section{Development of Amphibian Ear Vesicle}

were still quite imperfect in the formation of the separate chambers and the semicircular canals. So this year in carrying out the experiments described in the first part of the present paper the behavior of the specimens was eagerly watched, and the endeavor was made to determine the amount of alteration in position and defectiveness in form that is compatible with functional activity, involving the problem of the correlation between function and morphology. The observations made in the different experiments have been arranged and condensed as follows:

a Left ear vesicle removed; right ear vesicle loosened from skin and rotated, in six specimens around the vertical axis $180^{\circ}$ and in eight specimens around both the vertical and transverse axis $180^{\circ}$. As has already been shown these ear vesicles developed into labyrinths of varying degrees of perfection, some being completely normal in form and having apparently normal ganglion and nerve connection with the brain wall. (See Figs. 2, 3 and 4.) The behavior of all the specimens was uniform, both where the ear vesicle was rotated in one plane and where rotated in two planes; at the end of a week after the operation, when with a normally functionating labyrinth they should be able to swim freely and directly, they instead exhibit only irregular movements or spin around in spirals or circles. Their incoördinate movements continue, and at the end of a month there is no improvement; i.e, they behave exactly like specimens with both ear vesicles removed. Evidently ear vesicles thus treated do not perform their natural function.

$b$ Left ear vesicle removed; right ear vesicle fragmented by teasing between the points of two needles, the fragments left in place. Ten specimens were treated in this way, and were kept under observation four weeks, during which time they gave no evidence of any sense of equilibrium.

$c$ Right ear vesicle removed; left ear vesicle transplanted to the empty pocket on the right side. Five specimens were operated upon and observed for one month, at the end of which time they.were cut in serial sections, and it was found that the ear vesicles had developed into fairly complete labyrinths, but had maintained the characteristics of a left-sided organ. (Figs. 5 and 6.) 
Throughout the whole period of observation they had exhibited incoördinate movements, and at the end of that time they were unable to swim. This and the two previous operations indicated that rotation of an ear vesicle, or transplanting it from one side to the other, or fragmenting it was not compatible with the development of its function, in spite of the fact that the ear vesicle proceeded in its development and had become to all appearances almost a perfect labyrinth. In the next experiments less severe treatment was tried.

$d$ Left ear vesicle removed; right ear vesicle uncovered and carefully lifted out and then immediately placed back in its original position, the effort being made to do a minimum amount of injury. Of six specimens all exhibited symptoms of the absence of all sense of equilibrium.

In the experiments $a, b, c$ and $d$ there was the possibility of injury to both the nerve-ganglion connection and the ear vesicle. In the following experiments the effort was made to restrict the injury to one or the other.

$e$ Left ear vesicle removed; right ear vesicle uncovered and a fragment cut from the cephalic portion of its wall, care being used not to otherwise disturb the vesicle. Eight such specimens were kept five weeks, and none of them developed any sense of equilibrium, or were able to swim.

$f$ Left ear vesicle removed; right ear vesicle uncovered and a small piece cut from its caudal border, any further disturbance being avoided as in $e$. Eight specimens were operated upon, and after keeping them four weeks none of them could swim properly.

$g$ Left ear vesicle removed; longitudinal incision made through skin on right side just dorsal to ear vesicle, and needle passed down between the neural tube and ear vesicle and moved backward and forward so as to sever its nervous connection without otherwise disturbing the ear vesicle or loosening it from the skin. None of the four specimens studied swimmed properly, though one of them could swim somewhat, but was easily confused by any excitement and then made wild and ill directed movements. It was thought that the ear vesicles in these cases would escape injury; but examination of the specimens when cut in serial sections 
showed that they were not perfectly normal. This experiment might be repeated on a larger number of specimens and still greater care used in severing the nerve connection, in which case a perfect labyrinth could doubtless be obtained.

$h$ (Rana catesbiana) Left ear vesicle transplanted into another specimen, in a subdermal pocket in the region of the prootic ganglion between the right eye and ear vesicle, thus the host had three ear vesicles, two being on the right side. Twelve days after the operation three out of four specimens so treated exhibited incoördinate movements. Here we have to consider the crowding out of position of the normal right ear vesicle by the one transplanted near it.

$i$ Left ear vesicle removed; fine needle passed through the skin so as to make a small puncture in the right ear vesicle; on withdrawal of the needle the edges of the wound immediately close and there is no loss of cells from underneath or from the skin itself. Of four specimens at the end of one month three were able to swim, and this demonstrated the functional ability of an ear vesicle thus treated.

$j$ Left ear vesicle removed; small section of the covering skin removed so as to expose the right ear vesicle, but otherwise it is not disturbed and the nerve ganglion connection is left intact. Five specimens were kept under observation for one month, and four of them behaved throughout like those possessing one untouched normal ear vesicle; except for slight incoördination brought out by excitement they could swim properly.

On bringing together the results of these experiments, it becomes immediately apparent that almost any operative procedure carried out on young larvæ in the region of the ear vesicle seriously interferes with the development of the function of that organ. It is possible to lift a skin flap and expose it, and to make a needle puncture in it without destroying its subsequent usefulness; but any operation involving a loss of part of its wall or disturbing its position and nerve-connection with the brain causes apparently complete loss of function. The functional disturbance is out of al proportion to the histological condition. There may be a labyrinth that to all appearances is perfectly formed and that seems to 
have a normal nerve ganglion connection with the brain at the proper place, and yet the specimen may not have given signs of any functional activity on the part of that organ.

Spemann ${ }^{6}$ is doubtless mistaken in attributing the disturbance in equilibrium simply to the alteration in the planes of the canals. He reports some experiments in which at an early stage a skin flap was turned back, and the ear vesicle taken out and replaced in various positions; and in such specimens he observed faulty equilibrium, and on sectioning his material the vesicle seemed to lie in an abnormal position, and this he assumes to be the cause of the abnormal movements observed. On the one hand, wax plate reconstructions of misplaced ear vesicles show that in my cases they regain their proper position, and the canals eventually lie in their normal planes; the specimens nevertheless continue to make incoördinate movements. On the other hand, in those experiments where the normal position of the vesicle, as regards the planes of space, was undisturbed the results were equally serious. My own experiments suggest that the difficulty lies not so much with the end organ as with the central connections, and perhaps further experiments in that direction would furnish additional information upon this subject.

\section{CONCIUSIONS}

The primitive ear vesicle of the tadpole may be loosened from its normal position and rotated in various directions, so that its axes lie in abnormal planes, and notwithstanding such interference it eventually develops into a labyrinth which is right side up and exhibits the normal relations to the brain and the surrounding structures. When transplanted to the opposite side of the body, if placed in the acoustic region, it likewise assumes a normal posture. Judging from these facts, the posture of the labyrinth is controlled by its environment.

The "laterality" of the labyrinth is determined before the closure of the ear vesicle. When the left ear vesicle is transplanted

6Spemann, H., 'o6: Ueber embryonale Transplantation. Verhandl. der Gesell. Deutscher Naturf. u. Aerzte. 78 Vers. Stuttgart. 
to the right side it retains its characteristics as a left-sided organ, though it otherwise adapts itself to its new position in a normal manner.

The functional disturbance, in experiments on the ear vesicle, is out of all proportion to the histological appearances; any operation carried out in the acoustic region involving a loss of part of the wall of the ear vesicle, or disturbing its position, or nerve connection with the brain results in faulty equilibrium; absence of function was observed in cases where the labyrinth and its nerve connections seemed to have attained perfect histological development. 